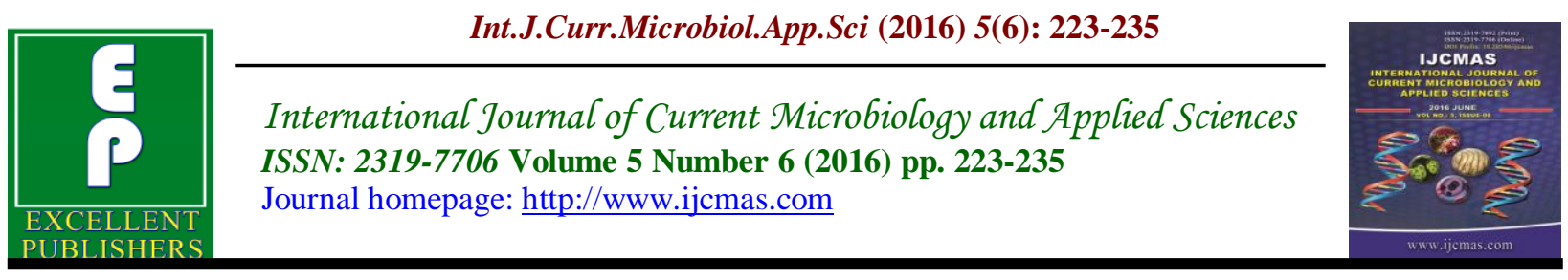

Original Research Article

http://dx.doi.org/10.20546/ijcmas.2016.506.026

\title{
Bacterial Microbiota Analysis Present in the Nose and Pharynx of a Mexican Young Population
}

\section{Ana Karina Rodríguez-Vicente ${ }^{1}$, Jaime Bustos-Martínez ${ }^{2}$, Dolores Reyes-Duarte ${ }^{3}$ and Teresita Sainz-Espuñes ${ }^{4} *$}

\author{
${ }^{1}$ Doctorado en Ciencias Biológicas y de la Salud. Universidad Autónoma \\ Metropolitana-Xochimilco. Mexico City, Mexico \\ ${ }^{2}$ Departamento de Atención a la Salud. Universidad Autónoma \\ Metropolitana-Xochimilco, Mexico City, Mexico \\ ${ }^{3}$ Departamento de Procesos y Tecnología. Universidad Autónoma \\ Metropolitana-Cuajimalpa, Mexico City, Mexico \\ ${ }^{4}$ Departamento de Sistemas Biológicos. Universidad Autónoma \\ Metropolitana-Xochimilco, Mexico City, Mexico \\ *Corresponding author email id:
}

\begin{abstract}
A B S T R A C T
\section{Keywords \\ Bacterial \\ Microbiota, \\ Nose and \\ Pharynx, \\ metagenomic \\ analysis.}

\section{Article Info}

Accepted:

12 May 2016

Available Online:

10 June 2016

Culture-independent microbiota is relatively unexplored in Mexican population. The aim of this study was to characterize the microbiota of Mexican young healthy adults by means of traditional culture and metagenomic analysis in order to provide novel insights and have a better understanding about the healthy baselines from which to detect differences associated with diseases. The bacterial microbiota of the nose and pharynx from 75 healthy nonsmoking Mexican young adults was examined by conventional cultures and cultureindependent methods. The hypervariable region (V6-V8) of the16S rRNA gene was PCR amplified from isolated DNA and DGGE analyzed, bands excised were sequenced and phylogenetic analysis was done. The study showed that the bacterial microbiota of the pharynx was richer than that of the nose. Using conventional culture methods results showed that gram positive Staphylococcus aureus and S. epidermidis were found in both niches and gram negative bacteria such as Escherichia coli, Klebsiella sp. and Moraxella sp. were the most abundant genera in the nose and Enterobacter sp. in the pharynx. Firmicutes and Proteobacteria phyla accounted for the majority of the bacteria detected in both niches. To our knowledge this is the first report describing partially the composition of and the variability within the nasopharyngeal microbiota of a Mexican young adult population and therefore we will be able to investigate other different cities and compared them to find out where are the highest microbial contaminated zones and take some hygienic measures in accordance to the normativity reports.
\end{abstract}

\section{Introduction}

The nostrils or anterior nares are the outermost segment of the nose and is considered a transition zone from the skin to the nasal cavity. Like skin, the nostrils contain sebaceous glands, sweat glands, and hairs and are lined by a keratinized, stratified squamous epithelium more similar to that of skin than to the mucus-producing, 
ciliated, columnar epithelium of the nasal cavity (Lemon, 2010; Wilson, 2005).

The nostrils help filter inhaled air, which contains low numbers of extremely diverse microbes (Lemon, 2010; Brodie et al., 2007; Fierer et al., 2008). The pharynx is constantly exposed to both inhaled and ingested microbes. This microbiota is influenced by different factors like age, immunological conditions, and the environment that in this particular case is highly polluted in Mexico City (Rosas et al., 2006; Secretaria de Medio Ambiente, 2012). The nostril and oropharynx are considered distinct habitats. While the pathogen Staphylococcus aureus colonizes both sites (Lemon, 2010, Widmer et al., 2008, Mertz, 2007, Wilson, 2005).

The knowledge on nose and pharynx microbiota has focused on pathogen carriage using traditional cultivation methods, however currently molecular approaches including DGGE 16S gene analysis, pyrosequencing, 16S rDNA PCR-RFLP, analysis of phylochip, High-Throughput Sequencing (Chakraborty et al., 2014; Yi et al., 2014, Ling et al., 2013; Aguirre et al., 2012; Brugger et al., 2012; Lemon et al., 2010). These methods have most used to study the relation between the dynamic equilibrium of human health and disease, being the pathogenic microorganisms the best studied. In a variety of environmental samples the study of the microbial diversity is accomplished by metagenomic DNA studies and also by traditional culture methods. The later poorly predicts resident microbiota (Hauser et al., 2014). Cloning and sequencing of $16 \mathrm{~S}$ genes amplified directly from different human sites such as the oral cavity for example, demonstrated that microbial diversity is by far more extensive compared to culture-based studies (Chakraborty et al., 2014).
The nostrils are known to harbor bacteria from the genera Corynebacterium, Propionibacterium, and Staphylococcus (Firmicutes and Proteobacteria phyla), including the important pathogen Staphylococcus aureus found by molecular methods (Lemon, 2010; Wilson, 2005). The nasal cavity appears dominated by resident aerobic microbiota as Corynebacterium spp. and Staphylococcus spp. detected by cultivation (Rasmussen et al., 2000). In the oropharynx species from the genera Streptococcus, Haemophilus, Neisseria are present, and to a lesser extent Staphylococcus and various anaerobic bacteria (Lemon, 2010; Wilson, 2005). Oropharynx is the site of carriage of many important human pathogens, including Streptococcus pneumoniae, Streptococcus pyogenes, Haemophilus influenzae, Neisseria meningitidis, Moraxella catarrhalis, and Staphylococcus aureus (Bogaert et al., 2011; Lemon, 2010; Mertz et al., 2007; Widmer et al., 2008; Wilson 2005).

The aim of this study was to investigate the microbiota of Mexican young healthy adults by means of traditional culture and metagenomic analysis in order to have a better understanding about the healthy baselines from which to detect differences associated with diseases. Our approach was chosen because this population has been scarcely studied in regard with children and older adults.

\section{Material and Methods}

\section{Ethic Statement and Ethical Approval}

Samples were collected in accordance with relevance guidelines for ethical research design, confidentiality and protection human subjects. Protocol was reviewed and approved by the ethics and biosafety committees of the Universidad Autónoma 
Metropolitana-Xochimilco (Hamdan et al., 2013). All procedures performed in studies involving human participants were in accordance with the ethical standards of the institutional and/or national research committee and with the 1964 Helsinki declaration and its later amendments or comparable ethical standards (World Medical Association Declaration of Helsinki Ethical Principles for Medical Research, 1964).

\section{Subjects and Sample Collection}

As in previous studies (Hamdan et al., 2013) informed consent was obtained from all individual participants for screening enrollment and specimen collection. Great care was taken to ensure that all people understood that they would participate as volunteers; no academic or economic incentives were offered.

Seventy five (75) healthy adult volunteers, whose ages between 18-25 years old were included between January and March of 2012. Criteria for participation were: no clinical signs of illness, no antibiotic therapy within 3 months before entering the study, no pregnancy or breast feeding and nonsmokers.

Separate swabs were used to collect the samples, one for the nostrils and the other for the posterior wall of the pharynx of each participant and were placed into enrichment media (tripticase soy broth) and non enrichment media (saline buffer solution). The pharynx posterior wall was swabbed without touching the tonsils, uvula, tongue, or other oral structures.

\section{Microbial Cultivation}

Nasal and pharynx swabs were first enriched by a 24 hours cultured at $37^{\circ} \mathrm{C}$ in tripticase soy broth and then plated onto a $5 \%$ sheep blood agar, chocolate agar, mannitol salt agar and Mac Conkey agar plates and then were incubated at $37^{\circ} \mathrm{C}$ for $24 \mathrm{~h}$; chocolate agar plates with a $5 \% \quad \mathrm{CO}_{2}$ atmosphere. Bacteria identification was based on colony morphology and bacteriological biochemical conventional tests (Holtz, 1993; Winn et al., 2006).

\section{Nucleic Acid Isolation}

Genomic DNA was extracted from the swabs collected in saline buffer solution and from the enrichment media from nose and pharynx using a commercial kit Fast ID Genomic DNA Extraction (Genetic ID NA Inc, USA) following the manufacturer's instructions including some modifications: ten microliters of proteinase $\mathrm{K}$ solution (10 $\mu \mathrm{g} / \mu \mathrm{l}), 5 \mu \mathrm{L}$ of lysostaphin solution $(0.5$ $\mu \mathrm{g} / \mu \mathrm{l})$ and $15 \mu \mathrm{L}$ of mutanolysin solution $(1 \mathrm{U} / \mu \mathrm{l})$ were added for cellular lyses.

\section{PCR Amplification}

Hypervariable region V6-V8 of the $16 \mathrm{~S}$ rRNA gene was amplified from the isolated genomic DNA using universal primers $968 \mathrm{f}$ 5'-AAC GCG AAG AAC CTT ACC-3' and 1401r 5'-GCG TGT GTA CAA GAC CC-3' (Ramírez-Saad et al., 2000). The gc968f forward primer contains additional 40 nucleotide GC-rich sequence the GC clamp for DGGE technic. Amplification was performed with a Whatman Biometra TProfessional Basic 96 gradient thermal cycler (Goettingen, Germany). Each mixture (25 $\mu$ l final volume) contained $1 \mu \mathrm{l}$ DNA template, $0.5 \mathrm{mM}$ primer concentration, 200 $\mathrm{mM}$ dNTPs, 1X PCR buffer and Q solution and $2.5 \mathrm{U}$ of Taq polymerase (Qiagen TaqPCR Core kit Cat. no. 201225, Qiagen GmbH, D-407224 Hilden ). DNA template was denatured for $5 \mathrm{~min}$ at $94^{\circ} \mathrm{C}$. To increase the amplification specificity and to reduce the formation of spurious byproducts, a "touchdown" PCR was performed. The 
initial annealing temperature used was $10^{\circ} \mathrm{C}$ above the expected annealing temperature $\left(65^{\circ} \mathrm{C}\right)$, and the temperature was decreased by $1{ }^{\circ} \mathrm{C}$ every second cycle until the touchdown temperature, $55^{\circ} \mathrm{C}$, was reached; then 10 additional cycles were carried out at $55^{\circ} \mathrm{C}$. Primer extension was performed at $72^{\circ} \mathrm{C}$ for $3 \mathrm{~min}$. The tubes were then incubated for $10 \mathrm{~min}$ at $72^{\circ} \mathrm{C}$ (final extension). Aliquots $(2 \mu \mathrm{l})$ of the amplification products were first analyzed by $1.5 \%$ agarose gels electrophoresis.

\section{Metagenome PCR-DGGE Analysis}

Profiling bacteria communities from the nose and pharynx samples was assayed by PCR-DGGE. PCR products were analyzed by Denatured Gradient Gel Electrophoresis (DDGE) by using a DCode mutation detection system (Bio-Rad Laboratories, Hercules, CA, USA). According to Muyzer (1993) cited by Morales (2009) $8 \%$ acrylamide gels (37:1 acrilamidebisacrilamide) were formed with a linear gradient between $30 \%$ and $60 \%$ denaturant; $100 \%$ denaturant is defined as $7 \mathrm{M}$ urea and $40 \%(\mathrm{v} / \mathrm{v})$ of formamide.

Gels were run at $85 \mathrm{~V}$ for $16 \mathrm{~h}$ in $1 \mathrm{x}$ TAE buffer $(40 \mathrm{mM}$ Tris, $20 \mathrm{mM}$ acetate, $1 \mathrm{mM}$ EDTA). DNA bands were visualized as previously described using the silver stain procedure (Sanguinetti et al., 1994).

\section{Sequencing of Excised DGGE Bands}

Prominent bands of the DGGE profiles were excised and reamplified for sequencing purposes, following a previously described procedure by Ramírez et al., (2000) and Aguirre-Garrido et al., (2012). Briefly, with a sterile blade, each band was eluted in $30 \mu \mathrm{l}$ of sterile water overnight at $4^{\circ} \mathrm{C}$.

Four microliter of the eluted DNA from each DGGE band was PCR reamplified using the conditions described above. The amplicons were size-checked for 500pb size and purified with a commercial kit EZ10 SPIN COLUM (BIO BASIC INC, Ontario Canada) following the manufacturer's instructions. Purified PCR products were sequenced by Macrogen Inc. (Seoul, Korea). When no significant sequence was obtained from a specific band, or more than one band was present, the cloning strategy was used in order to obtain a single amplicon for sequence.

\section{Cloning Procedures}

Size-checked purified 16S rRNA gene amplicons were cloned using a TOPO TA cloning kit (Invitrogen, Carlsbad, CA) following the manufacturer's instructions. Transformation was performed using competent $E$. coli TOP 10 cells provided by the manufacturer. Transformed cells were plated onto Luria-Bertani agar plates supplemented with kanamycin $(50 \mathrm{ug} / \mathrm{mL})$ and incubated overnight at $37^{\circ} \mathrm{C}$. For the screening, five colonies were picked from each plate and plasmid extraction was performed using the Gene $\mathrm{JET}^{\mathrm{TM}}$ Plasmid Miniprep Kit (Fermentas Life Science, USA). The sequence was done by Macrogen Inc. (Seoul, Korea) using the universal M13 primers as recommended.

\section{Phylogenetic Analysis}

According to Aguirre-Garrido et al., (2012) all obtained 16S rRNA sequences were checked for chimeric structures using the Bellerophon program (http://compbio.anu.edu.au/bellerophon/bellerophon.pl) (Huber et al., 2004; Domaizon et al., 2013) those identified as potential chimeras were discarded. All the sequences were assigned to species level by using the Identify tool of the Ribosomal database project (Cole et al., 2014), which also provides global sequence similarities. These sequences were compared using the Mega BLAST tool of the NCBI server (Table 2). 
Phylogenetic trees were built with partial 16S rRNA sequences (V6 - V8 regions), the trees included the obtained sequences and those of their close relatives, as selected from MegaBLAST tool of the NCBI server (Morgulis et al., 2008; Zhang et al., 2000). CLUSTAL $X$ was used for sequence alignment (Larkin et al., 2007) and MEGA program Neighbor-joining phylogenies were constructed with the Jukes-Cantor distance model and the Kimura two-parameter correction. Resulting dendrograms were tested with a Bootstrap analysis of 1000 replicates, as implemented in the MEGA software package (Tamura et al., 2013). Sequences of this study were deposited in the GeneBank database under the accession numbers: KR065528 through KR065575 (Table 2).

\section{Results and Discussion}

\section{Cultured Bacteria}

Eleven genera of cultured bacteria were identified from the nose and pharynx. Results showed that Staphylococcus epidermidis had the highest occurrence (60 $\%$ ) in the nose of the tested population while Staphylococcus aureus $(48 \%)$ in the pharynx. Almost the same genera were cultured from both niches, except for E. coli, that only was present in the nose (Table 1).

\section{Microbial Communities}

Profiles were generated by PCR DGGE of the V6-V8 regions of the $16 \mathrm{~S}$ rRNA gene. Metagenomic DNA from each sample of enrichment and non enrichment media was used as a target for amplifications. In general DGGE band patterns of enrichment media from the nose consisted in four or six strong bands and several less intense, while from non enrichment media only three or four intense bands were observed. Respect to the pharynx samples from enrichment media and non enrichment media, band patterns were similar and more complex compared with those from the nose samples and they consist of eight predominant bands and a number of bands with diverse intensities (Fig. 1).

Forty four bands from the nose and pharynx samples of enrichment and non enrichment media, and four additional bands of the isolated Staphylococcus strains were sequenced. Two phyla Firmicutes and Proteobacteria were found in these samples. Phylogenetic affiliations from sequences of DGGE bands are shown in Fig. 2 and were assigned to four major bacterial lineages. The most representative classes found in Firmicutes were Bacilli and Clostridia and Beta and Gamma-Proteobacteria for Proteobacteria phylum.

In this study the phylogenetic composition of the nares of a young Mexican population showed that the phylum Firmicutes with the genera Staphylococcus, Dolosigranulum y Clostridium and the phylum Proteobacteria with the genera Haemophilus, Klebsiella, Enterobacter and Citrobacter were found. In the pharynx the phylum Firmicutes with the genera Staphylococcus, Peptostreptococcus, Dolosigranulum and Bacillus and the phylum Proteobacteria with the genera Haemophilus, Neisseria and Kingella were also found (Table 2).

Analyses of the bacterial communities present in the nose and the pharynx were performed by culture-dependent and molecular-based methods extending our knowledge on the bacterial diversity of Mexican young adults.

In this study using culture-dependent techniques $S$. aureus which is part of the normal and asymptomatic microbial community was identified in the nose and the pharynx. Several reports (Kaspar et al., 
2015, Wos-Oxley et al., 2010 and Pettigrew et al., 2008) had pointed that the nose is by far the most common habitat for S. aureus, but our results show that the pharynx can be also a common habitat as well. It is important to address that in a previous reported study done by Hamdan et al., (2010) with a different healthy Mexican population and standard microbiological technics $S$. aureus was the most prevalent microorganism found in the pharynx with a higher occurrence compared with the nose. The results of this assay showed the same tendency confirming the high prevalence of $S$. aureus in the pharynx. Clinical implications of these findings are that healthy carriers could be spreading these bacteria among other compromised population.

Stearns et al., (2015) reported the genera Streptococcus, Bacillus, Corynebacterium, Pseudomonas, Dolosigranulum and
Propionibacterium using also cultured based methods. In our study the main genera found were, Streptococcus, Pseudomonas, Enterobacter, Aerococcus, Klebsiella, Moraxella and E. coli.

The present suggest that the presence of $E$. coli and other Enterobacteriaceae members in nose is probably due to fecal pollution suspended in the environment as described by Rosas et al., (2006). This author published that different E. coli pathotypes were mainly found in the air tested in Mexico City. As reported by Brodie et al., (2007) environmental conditions have a relationship with bacterial aerial dispersal because of the climate change and could alter the composition of microbial communities in some areas. Another possibility to explain the presence of Enterobacteriaceae is by hand to nose contamination (Wos-Oxley et al., 2010).

Table.1 Genera from identified cultured bacterial in the nose and pharynx

\begin{tabular}{|c|c|c|c|c|}
\hline \multirow[t]{4}{*}{ Genera } & \multicolumn{2}{|c|}{ Nose } & \multicolumn{2}{|c|}{ Pharynx } \\
\hline & Number & $\%$ & Number & $\%$ \\
\hline & of & of & of & of \\
\hline & samples & occurrence & samples & occurrence \\
\hline Staphylococcus aureus & 21 & 28 & 36 & 48 \\
\hline Staphylococcus epidermidis & 45 & 60 & 21 & 28 \\
\hline Staphylococcus & 5 & 6.7 & 5 & 6.7 \\
\hline chromogenes & & & & \\
\hline Streptococcus mitis & 17 & 22.7 & 24 & 32 \\
\hline Aerococcus viridians & 7 & 9.3 & 12 & 16 \\
\hline Enterobacter aerogenes & 19 & 25.3 & 14 & 18.7 \\
\hline Enterobacter cloacae & 3 & 4 & 1 & 1.3 \\
\hline Klebsiella sp. & 11 & 14.7 & 6 & 8 \\
\hline Moraxella sp. & 1 & 1.3 & 1 & 1.3 \\
\hline Escherichia coli & 1 & 1.3 & - & - \\
\hline Pseudomonas spp. & 1 & 1.3 & 2 & 2.7 \\
\hline
\end{tabular}


Int.J.Curr.Microbiol.App.Sci (2016) 5(6): 223-235

Table. 2 Taxonomic filiations of the bands obtained from the nose and pharynx samples.

\begin{tabular}{|c|c|c|c|c|}
\hline $\begin{array}{l}\text { Band } \\
\text { (accession number) }\end{array}$ & $\begin{array}{c}\text { Closest GenBank sequence } \\
\text { (accession number) }\end{array}$ & $\begin{array}{c}\text { Identity } \\
\%\end{array}$ & Phyla & Class \\
\hline $1 \mathrm{EN}^{\mathrm{a}}(\mathrm{KR} 065528)$ & Staphylococcus aureus (NR_115606.1) & $98 \%$ & Firmicutes & Bacilli \\
\hline 2 EN (KR065529) & Clostridium sordelli (JN048957.1) & $98 \%$ & Firmicutes & Clostridia \\
\hline 3 EN (KR065530) & Clostridium perfringens (JX267089.1) & $89 \%$ & Firmicutes & Clostridia \\
\hline 4 EN (KR065531) & Staphylococcus epidermidis (D83363.1) & $96 \%$ & Firmicutes & Bacilli \\
\hline 5 EN (KR065532) & Clostridium perfringens (JX267089.1) & $95 \%$ & Firmicutes & Clostridia \\
\hline 6 EN (KR065533) & Kleibsiella pneumoniae (KJ806418.1) & $99 \%$ & Proteobacteria & $\gamma$-Proteobacteria \\
\hline 7 EN (KR065534) & Clostridium sordelli (JN048957.1) & $99 \%$ & Firmicutes & Clostridia \\
\hline 8 EN (KR065535) & Kleibsiella oxytoca (JX412287.1) & $98 \%$ & Proteobacteria & $\gamma$-Proteobacteria \\
\hline 9 EN (KR065536) & Enterobacter aerogenes (HQ407223.1) & $96 \%$ & Proteobacteria & $\gamma$-Proteobacteria \\
\hline 10 EN (KR065537) & Staphylococcus aureus (NR_115606.1) & $96 \%$ & Firmicutes & Bacilli \\
\hline 11 EN (KR065538) & Clostridium sordelli (JN048957.1) & $93 \%$ & Firmicutes & Clostridia \\
\hline 12 EN (KR065539) & Citrobacter sp (KF374707.1) & $98 \%$ & Proteobacteria & $\gamma$-Proteobacteria \\
\hline 13 EN (KR065540) & Uncultured bacterium clone (KF073687.1) & $98 \%$ & Undefined & Undefined \\
\hline 14 EN (KR065541) & Kleibsiella pneumoniae (EU086097.1) & $98 \%$ & Proteobacteria & $\gamma$-Proteobacteria \\
\hline 15 EN (KR065542) & Kleibsiella sp. (KF914263.1) & $88 \%$ & Proteobacteria & $\gamma$-Proteobacteria \\
\hline 16 EN (KR065543) & Kleibsiella singaporensis (AF250286.1) & $99 \%$ & Proteobacteria & $\gamma$-Proteobacteria \\
\hline 17 EN (KR065544) & Enterobacter asburiae (EU239106.1) & $91 \%$ & Proteobacteria & $\gamma$-Proteobacteria \\
\hline 18 EN (KR065545) & Uncultured bacterium clone (EU777050.1) & $91 \%$ & Undefined & Undefined \\
\hline $19 \mathrm{EN}(\mathrm{KR} 065546)$ & Methylocaldum marinum (NR_126189.1) & $92 \%$ & Proteobacteria & $\gamma$-Proteobacteria \\
\hline $20 \mathrm{EP}^{\mathrm{b}}(\mathrm{KR} 065547)$ & Uncultured Haemophilus (KC348749.1) & $92 \%$ & Proteobacteria & $\gamma$-Proteobacteria \\
\hline 21 EP (KR065548) & Neisseria sp (KF33704.1) & $89 \%$ & Proteobacteria & $\beta$ - Proteobacteria \\
\hline 22 EP (KR065549) & Neisseria cinerea (KJ585681.1) & $99 \%$ & Proteobacteria & $\beta$ - Proteobacteria \\
\hline 23 EP (KR065550) & Neisseria sp (KC178546.1) & $99 \%$ & Proteobacteria & $\beta$ - Proteobacteria \\
\hline 24 EP (KR065551) & Neisseria cinerea $(\mathrm{KJ} 585681.1)$ & $100 \%$ & Proteobacteria & $\beta$ - Proteobacteria \\
\hline 25 EP (KR065552) & Neisseria sp (KC178546.1) & $94 \%$ & Proteobacteria & $\beta$ - Proteobacteria \\
\hline 26 EP (KR065553) & Uncultured bacterium clone (JF238960.1) & $99 \%$ & Undefined & Undefined \\
\hline 27 EP (KR065554) & Neisseria cinerea $(\mathrm{KJ} 585681.1)$ & $97 \%$ & Proteobacteria & $\beta$ - Proteobacteria \\
\hline 28 EP (KR065555) & Staphylococcus sp (AB845199.1) & $91 \%$ & Firmicutes & Bacilli \\
\hline 29 EP (KR065556) & Uncultured Haemophilus (KC348749.1) & $97 \%$ & Proteobacteria & $\gamma$-Proteobacteria \\
\hline 30 EP (KR065557) & Peptostreptococcus stomatis (NR_043589.1) & $99 \%$ & Firmicutes & Clostridia \\
\hline 31 EP (KR065558) & Uncultured Haemophilus (KC348749.1) & $99 \%$ & Proteobacteria & $\gamma$-Proteobacteria \\
\hline $32 \mathrm{NEN}^{\mathrm{c}}$ (KR065559) & Haemophilus parainfluenzae (JF506651.1) & $95 \%$ & Proteobacteria & $\gamma$-Proteobacteria \\
\hline 33 NEN (KR065560) & Clostridium sordelli (JN048957.1) & $96 \%$ & Firmicutes & Clostridia \\
\hline 34 NEN (KR065561) & Staphylococcus chromogenes (KJ83397.1) & $93 \%$ & Firmicutes & Bacilli \\
\hline 35 NEN (KR065562) & Staphylococcus epidermidis (D83363.1) & $93 \%$ & Firmicutes & Bacilli \\
\hline 36 NEN (KR065563) & Dolosigranulum pigrum (NR_113774.1) & $98 \%$ & Firmicutes & Bacilli \\
\hline 37 NEN (KR065564) & Dolosigranulum pigrum (NR_113774.1) & $95 \%$ & Firmicutes & Bacilli \\
\hline 38 NEN (KR065565) & Staphylococcus aureus (NR_115606.1) & $98 \%$ & Firmicutes & Bacilli \\
\hline $39 \mathrm{NEP}^{\mathrm{d}}(\mathrm{KR} 065566)$ & Staphylococcus aureus (KJ643929.1) & $100 \%$ & Firmicutes & Bacilli \\
\hline 40 NEP (KR065567) & Dolosigranulum pigrum (NR_113774.1) & $99 \%$ & Firmicutes & Bacilli \\
\hline 41 NEP (KR065568) & Peptostreptococcus anaerobius (AB640692.1) & $99 \%$ & Firmicutes & Clostridia \\
\hline 42 NEP (KR065569) & Kingella sp (LK985395.1) & $93 \%$ & Proteobacteria & $\beta$ - Proteobacteria \\
\hline 43 NEP (KR065570) & Kingella sp (LK985395.1) & $93 \%$ & Proteobacteria & $\beta$ - Proteobacteria \\
\hline 44 NEP (KR065571) & Bacillus sp. (KJ528251.1) & $92 \%$ & Firmicutes & Bacilli \\
\hline $45 \mathrm{Sa}^{\mathrm{e}}(\mathrm{KR} 065572)$ & Staphylococcus aureus (KJ643929.1) & $100 \%$ & Firmicutes & Bacilli \\
\hline $46 \mathrm{Sa}(\mathrm{KR} 065573)$ & Staphylococcus aureus (KJ643929.1) & $100 \%$ & Firmicutes & Bacilli \\
\hline $47 \mathrm{Se}^{\mathrm{f}}(\mathrm{KR} 065574)$ & Staphylococcus epidermidis (D83363.1) & $98 \%$ & Firmicutes & Bacilli \\
\hline $48 \mathrm{Se}(\mathrm{KR} 065575)$ & Staphylococcus epidermidis (D83363.1) & $97 \%$ & Firmicutes & Bacilli \\
\hline
\end{tabular}


Fig.1 DGGE profiles of V6-V8 regions of 16S rRNA gene. a) PCR products on lanes 1-4 were obtained from genomic DNA of nose enrichment media samples, lanes 5-8 shown PCR products obtained from genomic DNA of pharynx enrichment media samples. b) PCR products on lanes 1-6 were obtained from genomic DNA of nose non enrichment media samples, lanes 7-12 shown PCR products obtained from genomic DNA of pharynx non enrichment media samples. Lanes 13-15 correspond to Staphylococcus aureus genomic DNA obtained from isolated bacteria (lane 13) and S. epidermidis (lanes 14 and 15).
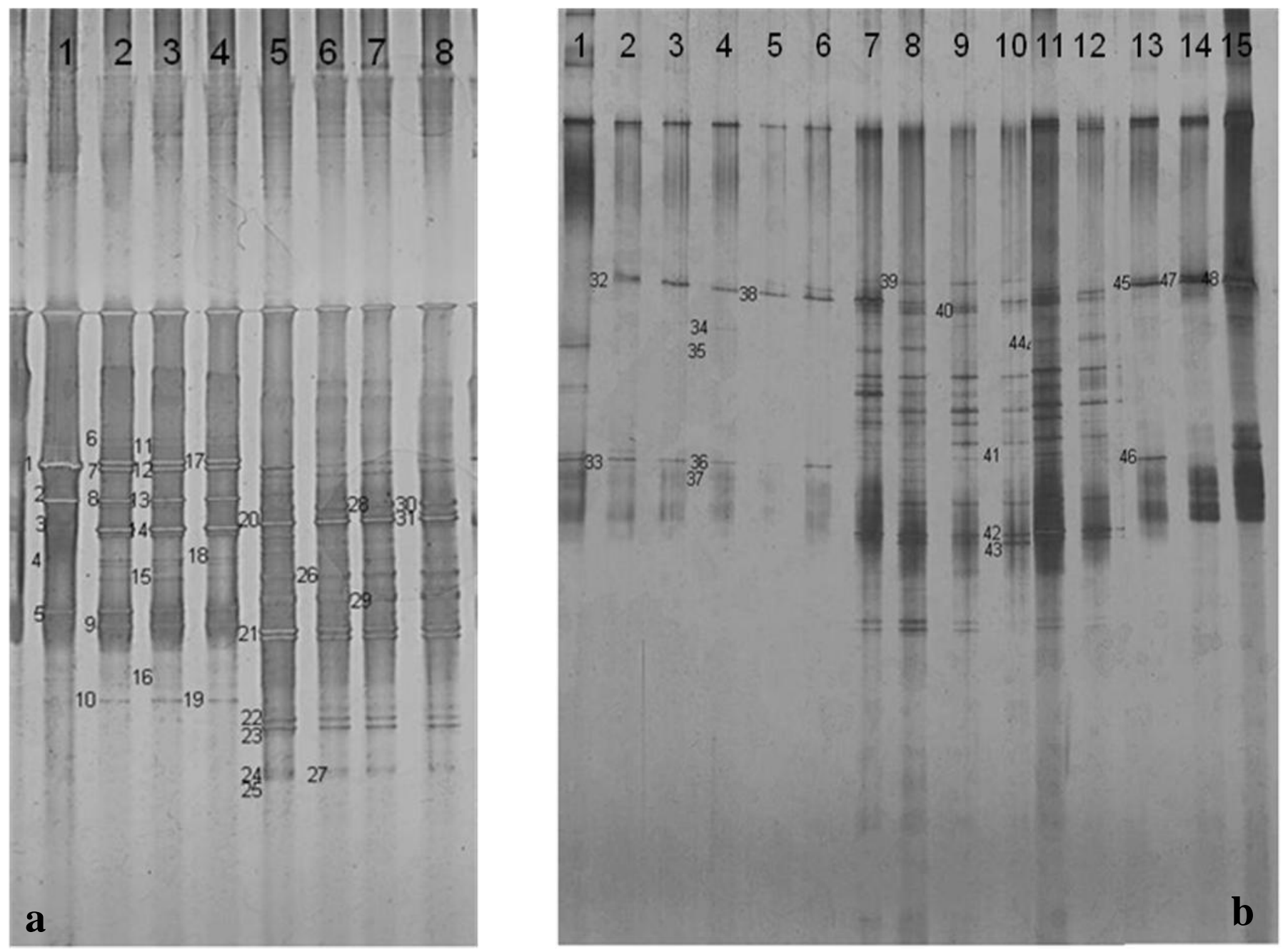
Fig.2 Sequencing of excised DGGE bands and related GeneBank sequences were used to create the neighbor-joining tree. Used sequences ( \pm 440 nucleotides) included the V6-V8 regions of the 16S rRNA gene. To identify the codes of excised bands, the letters correspond to the sample type: enrichment nose (EN), enrichment pharynx (EP), non enrichment nose (NEN) and non enrichment pharynx (NEP), (*) correspond to out-group sequence. The NCBI GenBank accession number for each sequence is shown in the parentheses.

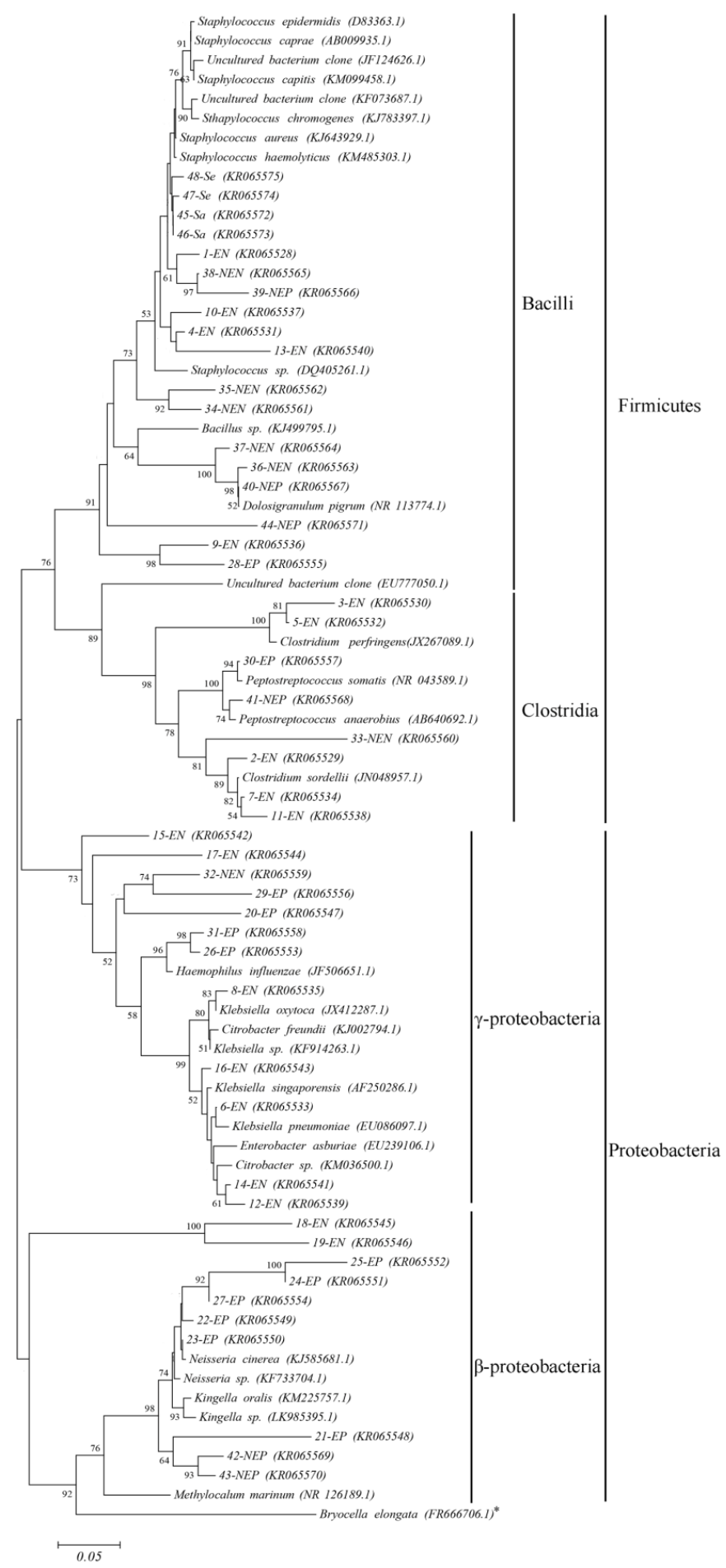


The present study findings in healthy young people matched with others authors, Yi et al., (2014) reported the genera Streptococcus, Moraxella, Haemophilus, Neisseria, Klebsiella, and Staphylococcus. Lemon et al., (2010) also describe the Staphylococcaceae family. Other culture independent studies described the ecology of the healthy nose microbiota, the majority of the rRNA sequences obtained from this part of the body belonged to different bacterial phyla such as: Actinobacteria (Gram positive organisms for example Corynebacteria), Firmicutes (Gram positive organisms commonly Staphylococcus and Streptococcus) (Yi et al., 2014; Chaban et al., 2013, Bogaert et al., 2011; Charlson et al., 2011; Frank et al., 2010). At the genus level, Corynebacterium spp., Propionibacterium spp. and Staphylococcus spp. Streptococcus, Haemophilus, Moraxella are prominent members of the upper respiratory tract microbiome (Yi et al., 2014; Costello et al., 2009; Frank et al., 2010; Grice et al., 2009; Lemon et al., 2010).

This study had some methodological limitations, the $16 \mathrm{~S}$ rRNA V6-V8 region was the only one studied, but despite of this, it includes a great diversity of microorganisms some of them were uncultured ones.

However this type of study may be a reference to characterize an important part of the microbiota found in the nose and pharynx of healthy young people and compare the pathogens in healthy carriers with the natural microbiota in order to predict potential risk of infections (Johannessen, et al., 2012). To our knowledge this is the first report describing partially the composition of and the variability within the nasopharyngeal microbiota of a Mexican young adult population and therefore we will be able to investigate other different cities and compared them to find out where are the highest microbial contaminated zones and therefore take some hygienic measures in accordance to the normativity reports, besides the clinical implications that healthy carriers could spread these bacteria among other susceptible compromised population.

\section{Acknowledgements}

We thank PhD. Felix Aguirre-Garrido for his technical support and bioinformatic processing also we thank $\mathrm{PhD}$. Antonio Gonzalez for his bioinformatic processing manuscript suggestions. AK RodríguezVicente is a Ph.D. student at the Doctorado en Ciencias Biologicas of Universidad Autonoma Metropolitana, Unidad Xochimilco and was supported by grant 222840 of CONACYT, Mexico.

\section{References}

Aguirre-Garrido, J.F., Montiel-Lugo, D., Hernández-Rodríguez, C., TorresCortes, G., Millán, V., Toro, N., Martínez-Abarca, F., Ramírez-Saad, H.C. 2012. Bacterial community structure in the rhizosphere of three cactus species from semi-arid highlands in central Mexico. Antonie van Leeuwenhoek, 101(4): 891-904.

Bogaert, D., Keijser, B., Huse, S., Rossen, J., Veenhoven, R. 2011. Variability and Diversity of Nasopharyngeal Microbiota in Children: A Metagenomic Analysis. PLoS One, 6 : e17035. doi:10.1371/journal.pone.0017035.

Brodie, E.L., DeSantis, T.Z., Parker, J.P., Zubietta, I.X., Piceno, Y.M., Andersen, G.L. 2007. Urban aerosols harbor diverse and dynamic bacterial populations. Proc. Natl. Acad. Sci., 
USA, 104: 299 -304.

Brugger, S.D., Frei, L., Frey, P.M., Aebi, S., Mühlemann, K., Hilty, M. 2012. 16S rRNA terminal restriction fragment length polymorphism for the characterization of the nasopharyngeal microbiota. PLoS One, 7(12): e52241. doi: 10.1371/journal.pone.0052241.

Chaban, B., Albert, A., Links, M.G., Gardy, J., Tang, P., Hill, J.E. 2013. Characterization of the Upper Respiratory Tract Microbiomes of Patients with Pandemic H1N1 Influenza. PLoS ONE, 8: e69559. doi:10.1371/journal.pone.0069559.

Chakraborty, S., Persaud, V., Vanegas, S., Gautier, G., Esiobu, N. 2014. Analysis of the human Oral Microbiome of smokers and non smokers using PCR-RFLP and Ribotyping. Adv. Microbiol., 4: 681691.

Doi.org/10.4236/aim.2014.410073.

Charlson, E.S., Bittinger, K., Haas, A.R. et al., 2011. Topographical Continuity of Bacterial Populations in the Healthy Human Respiratory Tract. Am. J. Respir. Crit. Care Med., 184: 957-963 doi: 10.1164/rccm.2011040655OC.

Cole, J.R., Wang, Q., Fish, J.A. et al. 2014. Ribosomal Database Project: data and tools for high throughput rRNA analysis. Nuc. Ac. Res., 42: D633D642. doi:10.1093/nar/gkt1244.

Costello, E.K., Lauber, C.L., Hamady, M., Fierer, N., Gordon, J.I., Knight, R. 2009. Bacterial community variation in human body habitats across space and time. Sci., 326(5960): 16941697.

Domaizon, O., Savichtcheva, D., Debroas, F., Arnaud, C., Villar, C., Pignol, B., Alric, Perga, M.E. 2013. DNA from lake sediments reveals the long-term dynamics and diversity of Synechococcus assemblages. Biogeosci., 10: 3817-3838.

Fierer, N., Liu, Z., Rodriguez-Hernandez, M., Knight, R., Henn, M., Hernandez M.T. 2008. Short-term temporal variability in airborne bacterial and fungal populations. Appl. Environ. Microbiol., 74: 200 -207.

Frank, D.N., Feazel, L.M., Bessesen, M.T., Price, C.S., Janoff, E.N., Pace, N.R. 2010. The Human Nasal Microbiota and Staphylococcus aureus Carriage. PLoS One, 5: e10598. doi:10.1371/journal.pone.0010598.

Grice, E.A., Kong, H.H., Conlan, S., Deming, C.B., Davis, J., Young, A.C., NISC. Comparative Sequencing Program, Bouffard GG, Blakesley RW, Murray PR, Green ED, Turner ML, Segre JA. 2009. Topographical and temporal diversity of the human skin microbiome. Sci., 324: 1190-1192. doi:10.1126/science.1171700.

Hamdan-Partida, A., Sainz-Espuñes, T., Bustos-Martinez, J. 2010. Characterization and persistence of Staphylococcus aureus strains isolated from the anterior nares and throats of healthy carriers in a Mexican community. J. Clin. Microbiol., 48: 1701-1705.

Hamdan-Partida, A., Sainz-Espuñes, T. and Bustos-Martínez, J. (2013). Isolation of community-acquired methicillinresistant Staphylococcus aureus in healthy carriers in a Mexican community. Int. J. Infect. Dis., 18: 22-26.

Hauser, L.J., Feazel, L.M., Ir, D., Fang, R. et al. 2014. Sinus culture poorly predicts resident microbiota. Int Forum Allergy Rhinol., 5(1): 3-9. doi: 10.1002/alr.21428.

Holtz, J.D. 1993. Bergey's Manual of 
Determinative Bacteriology, 9th edn. Williams and Wilkins, Baltimore.

Huber, T., Faulkner, G., Hugenholtz, P. 2004. Bellerophon; a program to detect chimeric sequences in multiple sequence alignments. Bioinformatics, 20: 2317-2319.

Johannessen, M., Sollid, J.E., Hanssen, A.M. 2012. Host- and microbe determinants that may influence the success of $S$. aureus colonization. Front Cell Infect. Microbiol., 2: 56. doi: 10.3389/fcimb.2012.00056.

Kaspar, U., Kriegeskorte, A., Schubert, T., Peters, G., Rudack, C., Pieper, D. et al. 2015. The culturome of the human nose habitats reveals individual bacterial fingerprint patterns. Environ. Microbiol., http://dx.doi.org/10.1111/14622920.12891.

Larkin, M.A., Blackshields, G., Brown, N.P. et al. 2007. Clustal W and Clustal X version 2.0. Bioinformatics, 23: 2947-2948.

doi:10.1093/bioinformatics/btm404.

Lemon, K.P., Klepac-Ceraj, V., Schiffer, H.K., Brodie, E.L., Lynch, S.V., Kolter, R. 2010. Comparative analyses of the bacterial microbiota of the human nostril and oropharynx. mBio 1: e00129-00110.

Ling, Z., Liu, X., Luo, Y,. Yuan, L., Nelson, K.E,. Wang, Y., Xiang, C., Li, L. 2013. Pyrosequencing analysis of the human microbiota of healthy Chinese undergraduates. BMC Genomics, $\quad 14: 390 . \quad$ doi: 10.1186/1471-2164-14-390.

Mertz, D., Frei, R., Jaussi, B. et al. 2007. Throat swabs are necessary to reliably detect carriers of Staphylococcus aureus. Clin. Infect. Dis., 45: 475-477.

Morales-Jiménez, J., Zúñiga, G., VillaTanaca, L., Hernández-Rodríguez, C.
2009. Bacterial Community and Nitrogen Fixation in the Red Turpentine Beetle, Dendroctonus valens LeConte (Coleoptera: Curculionidae: Scolytinae). Micro. Ecol., 58(4): 879-891.

Morgulis, A., Coulouris, G., Raytselis, Y., Madden, T.L., Agarwala, R., Schäffer, A.A. 2008. Database indexing for production MegaBLAST searches. Bioinformatics 24: 1757-1764. Doi: 10.1093/bioinformatics/btn322.

Muyzer, G., de Waal, E.C., Uitterlinden, A.G. 1993. Profiling of complex microbial populations by denaturing gradient gel electrophoresis analysis of polymerase chain reactionamplified genes coding for $16 \mathrm{~S}$ rRNA. Appl. Environ. Microbiol., 59: 695-700.

Pettigrew, M.M., Gent, J.F., Revai, K., Patel, J.A., Chonmaitree, T. 2008. Microbial interactions during upper respiratory tract infections. Emerg. Infect. Dis., 14: 1584-1591.

Ramírez-Saad, H.C., Sessitsch, A., de Vos, W.M., Akkermans, A.D.L. 2000. Bacterial Community Changes and Enrichment of Uncultured Burkholderia-like Bacteria Induced by Chlorinated Benzoates in a PeatForest Soil-microcosm. System Appl. Microbiol., 23: 591-598.

Rasmussen, T.T., Kirkeby, L.P., Poulsen, K., Reinholdt, J., Kilian, M. 2000 Resident aerobic microbiota of the adult human nasal cavity. APMIS, 108: 663-675.

Rosas, I., Salinas, E., Martínez, L. et al. 2006. Urban dust fecal pollution in Mexico City: antibiotic resistance and virulence factors of Escherichia coli. Int. J. Hyg. Environ. Health, 209: 461-470.

Sanguinetti, C.J., Dias-Neto, E., Simpson, 
A.J.G. 1994. Rapid silver staining and recovery of PCR products separated on polyacrylamide gels. BioTechniques 17: 915-919.

Secretaria de Medio Ambiente del Distrito Federal (SMADF). 2012. La calidad del aire en la Ciudad de México informe (2011). http://www.aire.df.gob.mx Accessed 15 April 2015.

Stearns, J.C., Davidson, C.J., McKeon, S., Whelan, F.J. et al. 2015. Culture and molecular-based profiles show shifts in bacterial communities of the upper respiratory tract that occur with age. ISME J., 9(5): 1268. doi: 10.1038/ismej.2015.49.

Tamura, K., Stecher, G., Peterson, D., Filipski, A., Kumar, S. 2013. MEGA6: Molecular Evolutionary Genetics Analysis Version 6.0. Mol. Biol. Evol., 30: 2725-2729.

Widmer, A.F., Mertz, D., Frei, R. 2008. Necessity of screening of both the nose and the throat to detect methicillin-resistant Staphylococcus aureus colonization in patients upon admission to an intensive care unit. J. Clin. Microbiol., 46: 835.

Wilson, M. 2005. Microbial inhabitants of humans: their ecology and role in health and disease. Cambridge University Press Cambridge United Kingdom.

Winn, W.Jr., Allen, S., Janda, W., Koneman, E., et al. 2006. Koneman's Color atlas and textbook of diagnostic microbiology. Sixth Ed. Lippincott Williams \& Wilkins, Baltimore, Md.

World Medical Association Declaration of Helsinki Ethical Principles for Medical Research Involving Human Subjects Adopted by the 18th WMA General Assembly, Helsinki, Finland, June 1964.

Wos-Oxley, M.L., Plumeir, I., von Eiff, C. et al. 2010. A poke into the diversity and associations within human anterior nare microbial communites. ISME J., 4: 839-851.

Yi, H., Yong, D., Lee, K., Cho, Y.J., Chun, J. 2014. Profiling bacterial community in upper respiratory tracts. BMC Infect. Dis., 14: 583. doi: 10.1186/s12879-014-0583-3.

Zhang, Z., Schwartz, S., Wagner, L., Miller, W. 2000. A greedy algorithm for aligning DNA sequences. J. Comput. Biol., 7: 203-214.

\section{How to cite this article:}

Teresita Sainz-Espuñes. 2016. Bacterial Microbiota Analysis Present in the Nose and Pharynx of a Mexican Young Population. Int.J.Curr.Microbiol.App.Sci. 5(6): 223-235. doi: http://dx.doi.org/10.20546/ijcmas.2016.506.026 